Funtion that regulation of the dose in which the rooreb of recendil trentment consists.

The doctrines of cutaneous therapeutics cannot, however, bo aid to be settled. During the preparation of these papers, a communication has appeared in the Monthly Journal of Medicine (January 185̃), from the pen of no loss important a writer than Professor Bennett of Edinburgh, "On the Treatment of the more Common Forms of Bkin Disease met with in Edinburgh," in which the accomplished author certainly lays down rules about as contrary to those which I have learned to respect, as is possible in the nature of things. The cases on which this practice is founded have presented themselres "since the addition of ward for skin diseases to the clinical department of the Royal Infirmary". How many months this has been added does not appear, neither are we told how many patients have been under treatment; but all I have at present to cay, in reference to Dr. Bennett's views and practice, is, that thirty years ago my own views very nearly corresponded with his in many points; my practice did not posentially differ: but the utter failure of topical treatment in hundreds of cases led me to study more carefully the pathology of these diseases; and, directing my remedies to the condition of the circulating fluids as the origin of local disease, I have been successful, not only in bundreds, but in thousands of cases; and, instead of having to regret, as formerly, that, by restoring the skin, I had destroyed the health, I have generally found that the freedom from skin disease has been coeval with, and dependent on, the permanent improvement of the health.

Alfred Place, Bedford Square, Nurch 1 s55.

\section{CASE OF SCIRRHUS IN THE DUODENUM: JAUNDICE.}

By PHILIP H. WILLIANS, M.D.

History. Rebecca C., aged 40 years, complained of having suffered from dyspeptic symptoms for several years, but did not remember to have been laid aside by any special attack until the present illncss. The appetite and strength became gradually impaired, and the flesh wasted.

Present Attack. Commenced, about eight weeks ago, with vomiting of slightly discoloured thin fluid, preceded, accompanied, and followed by uneasiness in the epigastric region. A blister had been applied over the seat of distress, and pills had been taken without any benefit. When I first saw the patient, about fire weeks ago, the skin was uniformly jaundiced. The flowing of thin dark fluid from the stomach was frequent. There was uneasiness at the epigastrium, but no decided pain nor tenderness on pressure. The abdomen was flat: the sounds, on percussion, in all the regions, were normal. No tumour of any kind could be detected. There were no spasms, no gall-stones, no ferer-in fact, no indications from which the true pathology of the case could be deduced. The general symptoms were simply those that attend the absorption of bile, namely, thirst, furred tongue, dark urine, and constipation.

Treatment. Small doses of calomel and henbane were given every four hours for two days, with a mixture containing prussic acid, bicarbonate of potass, and spirit of nitric ether. Diet, beef-tea. The bowels acted; but, instead of presenting the clay-like appearance which I expected, the motions consisted of a dark fluid somewhat similar to that which flowed from the stomach : it differed in being a little thicker and offensire, the fluid from the stomach being perfectly free from odour. The sickness was allayed so that a cup of beef-tea wis retained for six or eight hours; but the relief was only temporary. At the end of a week, the jaundice, with the other symptoms, remained. As no pathological cause could be discovered, an unfarourable prognosis was given, and, at the end of a month, was verified by the death of the patient. The vomiting became more frequent, so that no nourishment could be conrejed into the syetem. Inmscintion made steady progress, and exhaustion became complete.

Post Mortem. When the abdomen was opened, the duodenum was lying where the transverse colon should hare been found, and formed a bag which looked exactly like a second smaller stomach, and contained, as did the stomach itself, a quantity of dark thin fluid. On tracing the duodonum downwards, a scirrhous deposit, about the size of a walnut, was found in the gut, belowo the point where the biliary and pancreatic ducts enter. The disease seemed to have commenced in the wall of the gut next to the pancreas, into the head of which the deposit had slightly extended. The remainder of the small intestines, together with the whole of the large intestines, were remarkably diminished in calibre. The liver was congested, but quite free from disease. The gall-bladder was full. All the viscera were healthy. The scirrhous mass in the duodenum almost blocked up the passage, so that the bile which was constantly secreted was passed uproards into the distended portion of the duodenum, where it lodged (before reaching the stomach, and being ejected) for a sufficient length of time to allow absorption of the colouring matter to take place. The pylorus was quite healthy.

Dispcnsary, Worcester, March 1855.

\section{PERISCOPIC REVIEW.}

\section{SURGERY.}

\section{GLEANINGS FROM THE JOURNALS.}

SURGICAT, TREATMENT OF ABSCESS OF THE BREAST.

The surgical treatment of mammary abscess forms the subject of a paper by M. Chassaicinac in the Gazette Médicale for January 2ith and 2ith, 1855.

The author makes the following classification of these tumours: 1. Abscesses external to the gland (perimammary); 2. Abscess within the gland (endomammary).

The first class comprehends subcutaneous and subglandular obscesses. The subcutaueous abscesses are divided into simple phlermonous, lymphatic, and diffused. The subglandular abscesses are either simple phlegmonous, or hygromatic-i.e., seated in the submammary serous tissue.

The endomammary abscesses are divided into canalicular and interlobular.

1. Perimanmary Abscesses. Subcutancous abscess of the lymphatic or angeioleucitic kind is one of the most common forms of mammary abscess. Its symptoms are, rigors at the commencement; redness and nore or less swelling of irregularly arranged parts of the breast, or reddish streaks proceeding larly arranged parts of the axillary gland; painful engorgefrom the breast towards the axillary gland; painful engorgement of the circumscribed, and independent of the gland.

Phlegmonous perimammary subcutaneous abscess is also very common, and is distinguished by pain, heat, and swelling; by the formation of a projection corresponding to the part of the breast which is most hard and red; by the generally large size of the abscess; and by its being generally alone.

Perimammary diffused abscess commences with rery acuto lancinating pain, and a sense of violent constriction of the gland; a diffused erythematous redness covers the breast; the organ swells like a sponge; and the pulse becomes small, freorgan swe compressible: suppuration is soon established; the skin is perforated at several points, so as to disclose the cellnlar tissue dead, and as if imbued with a milky pus : finally, the the dead, and actaneous cellular tissue is attacked, and the gland is as it were dissected out by the successive death of the parts invaded.

Subglandular abscesscs of the phlegmonous kind commence with general swelling of the breast, and deep-seated pain, and the ordinary general symptoms of rigor, fever, etc. When finctuation is formed, there is an cedematous state of the breast or the adjacent parts. Fluctuation cannot be readily detectod unless by palpation at the lateral parts of the breast.

'The symptoms of hygromatic posteromammary abscess are nearly the same as those of the phlegmonous form; and, if the 